\title{
Dienamine-catalyzed nitrone formation via redox reaction
}

Americo J. Fraboni, and Stacey E. Brenner-Moyer*

Department of Chemistry, Rutgers University, Newark

73 Warren Street, Newark, NJ 07102, USA

seb244@rutgers.edu 
Contents

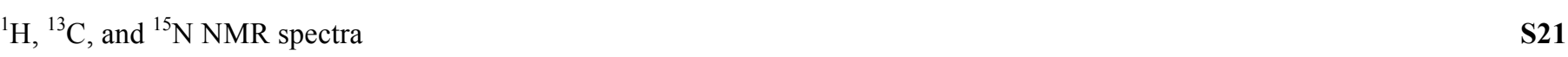

HPLC Chromatograms

S36 

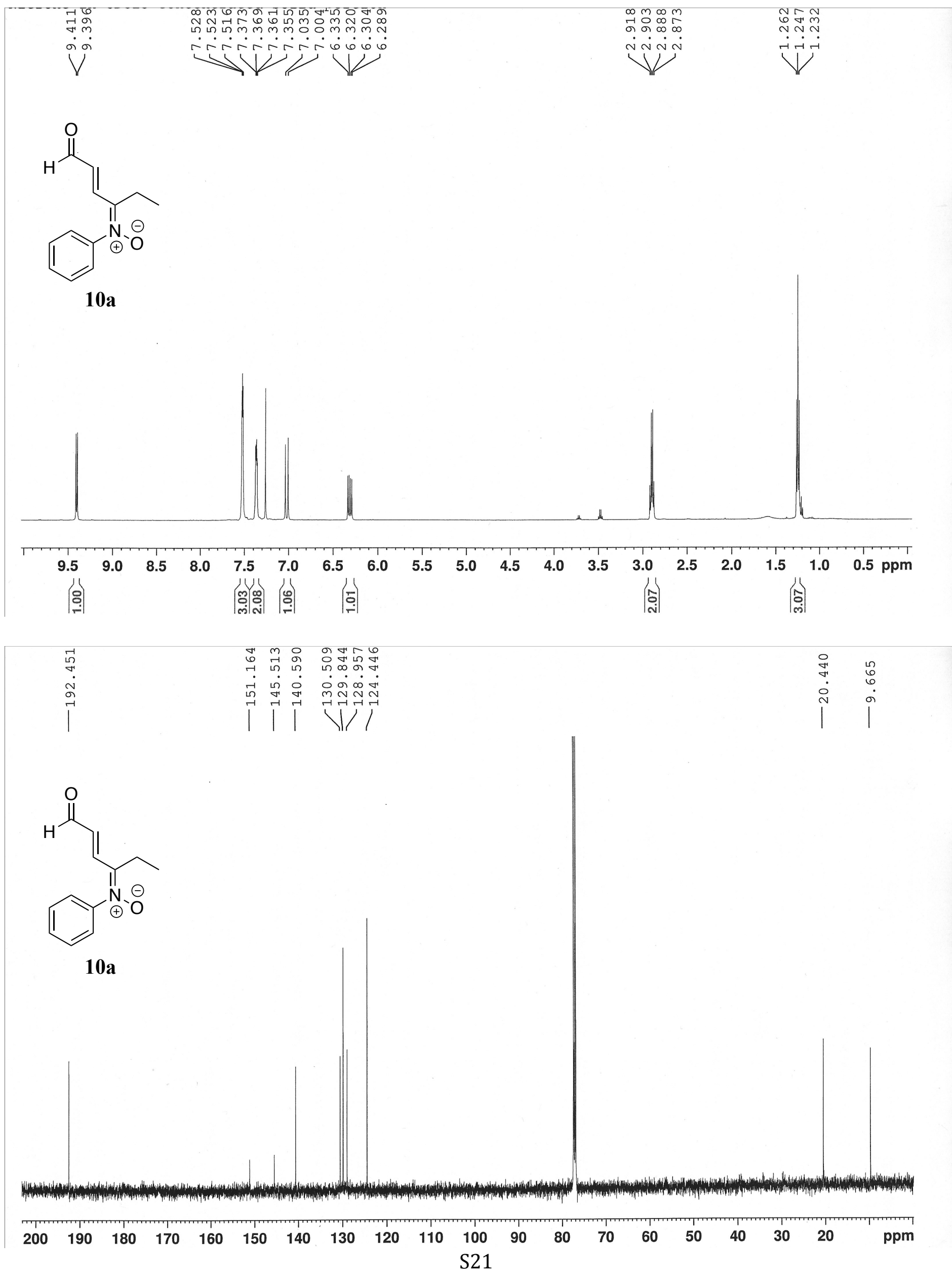


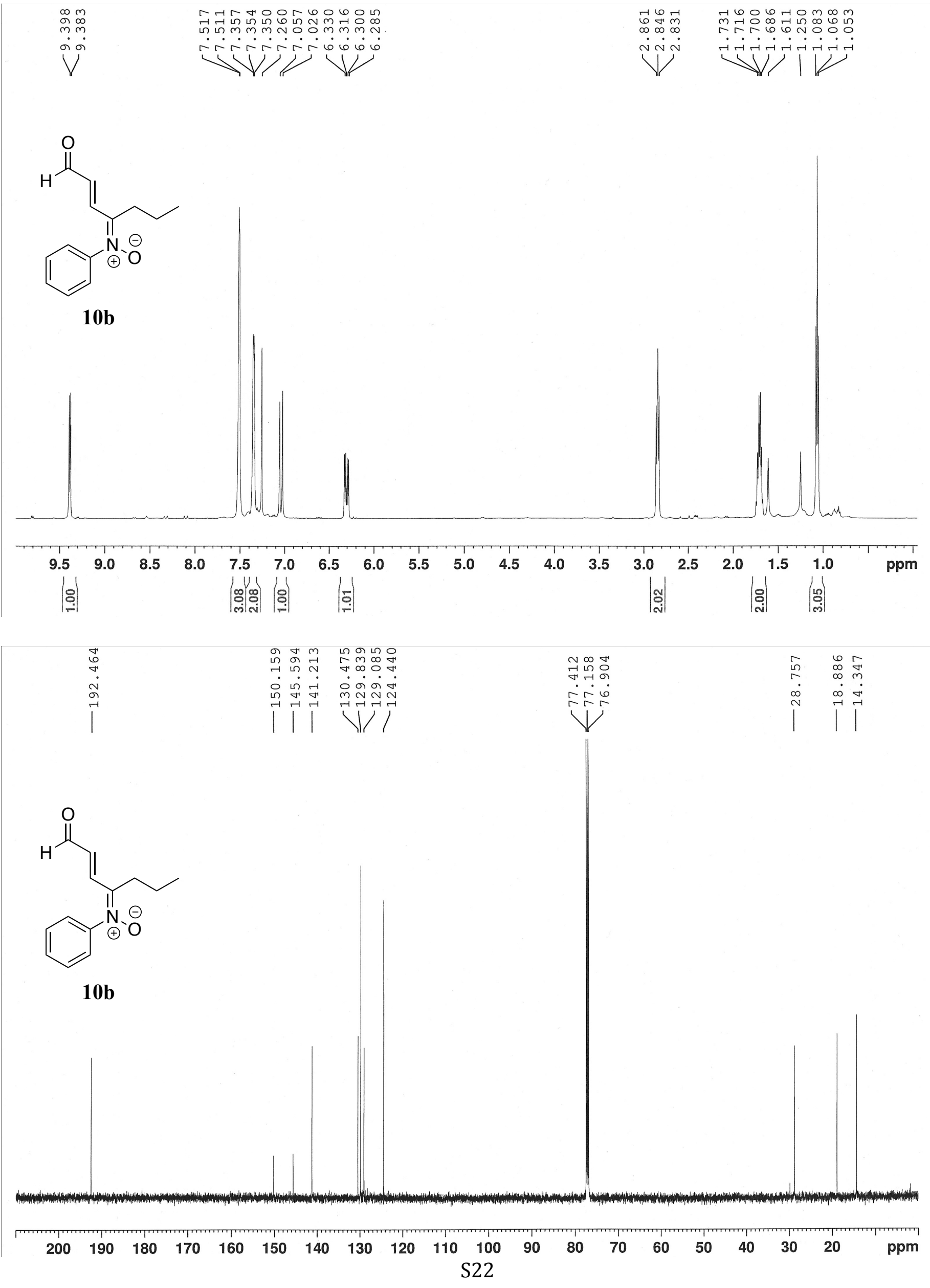




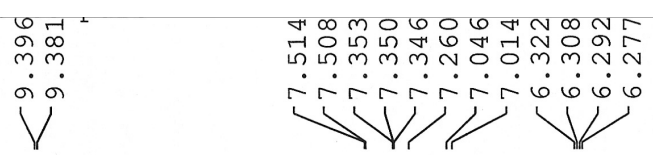

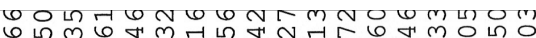
○ мं<smiles>CCCCCCCC(/C=C/C=O)=[N+]([O-])c1ccccc1</smiles>

10c
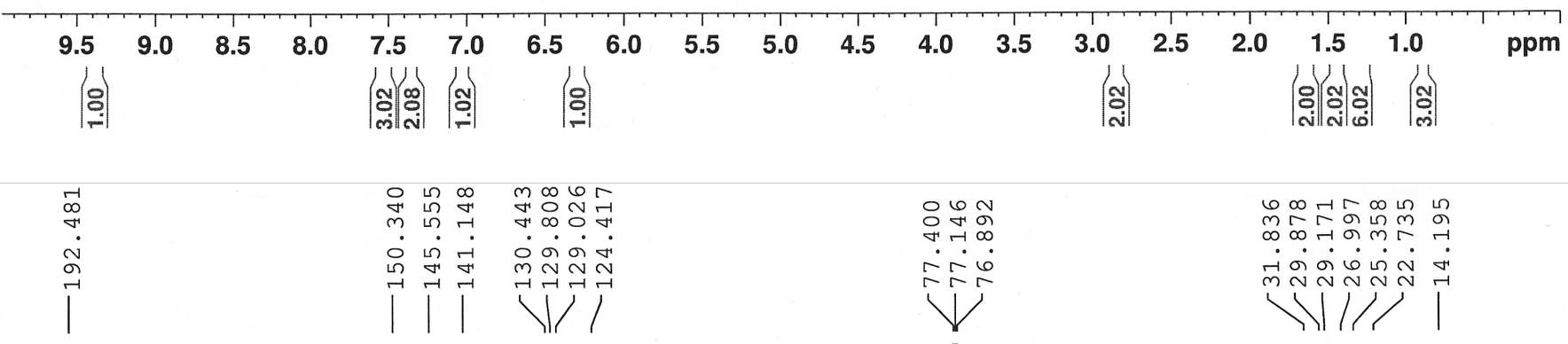

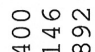

다일

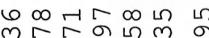
क III<smiles>CCCCCCCC(/C=C/C=O)=[N+]([O-])c1ccccc1</smiles>

10c
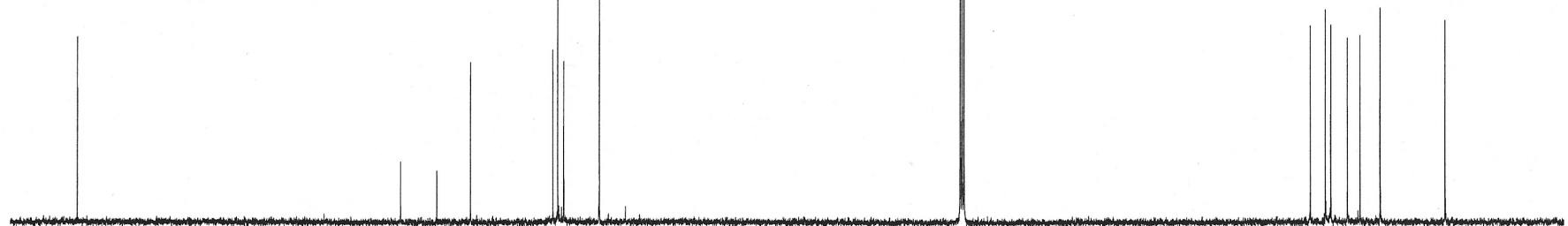

Tr 


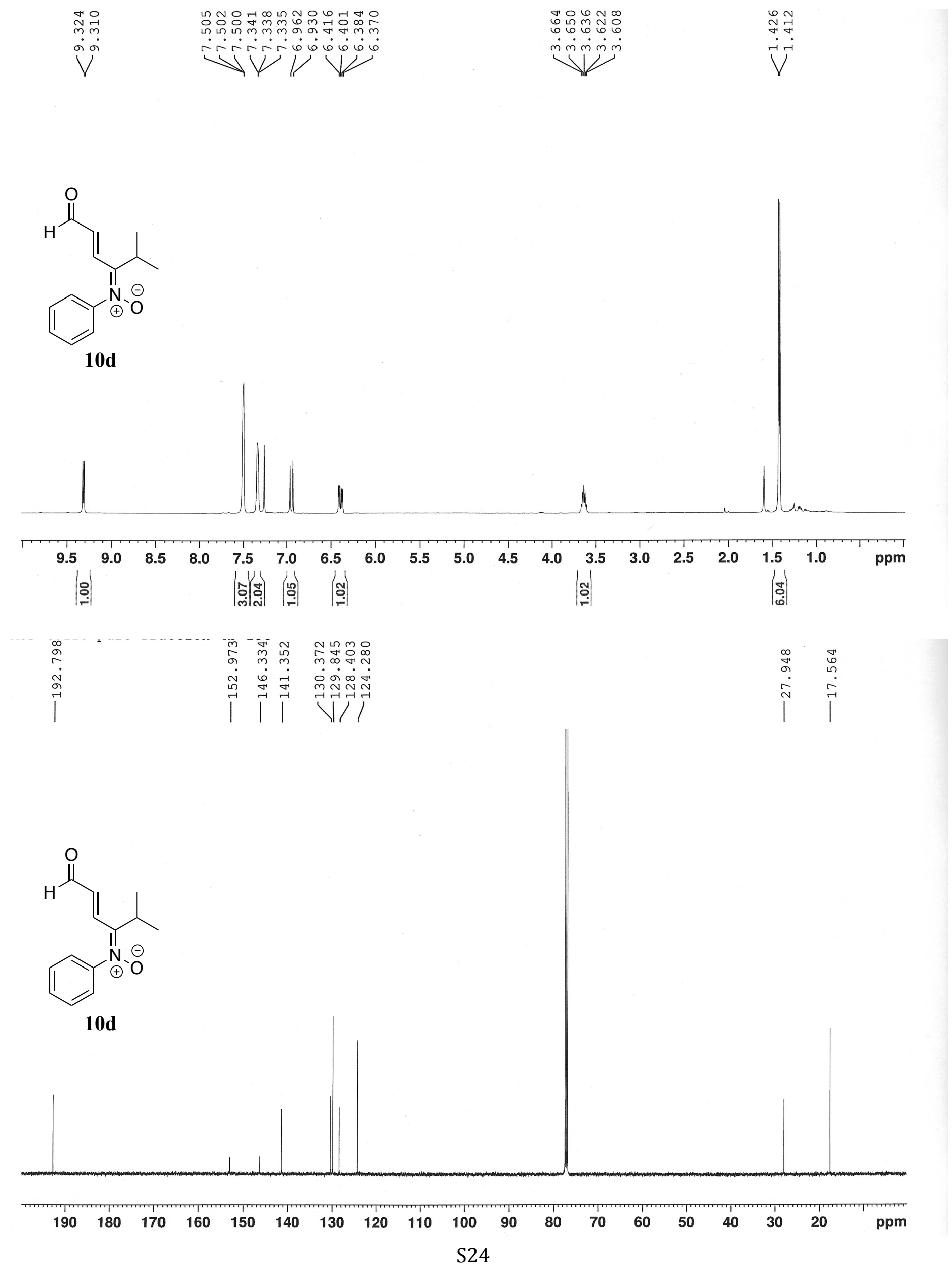


<smiles>O=C/C=C/C(Cc1ccccc1)=[N+]([O-])c1ccccc1</smiles>
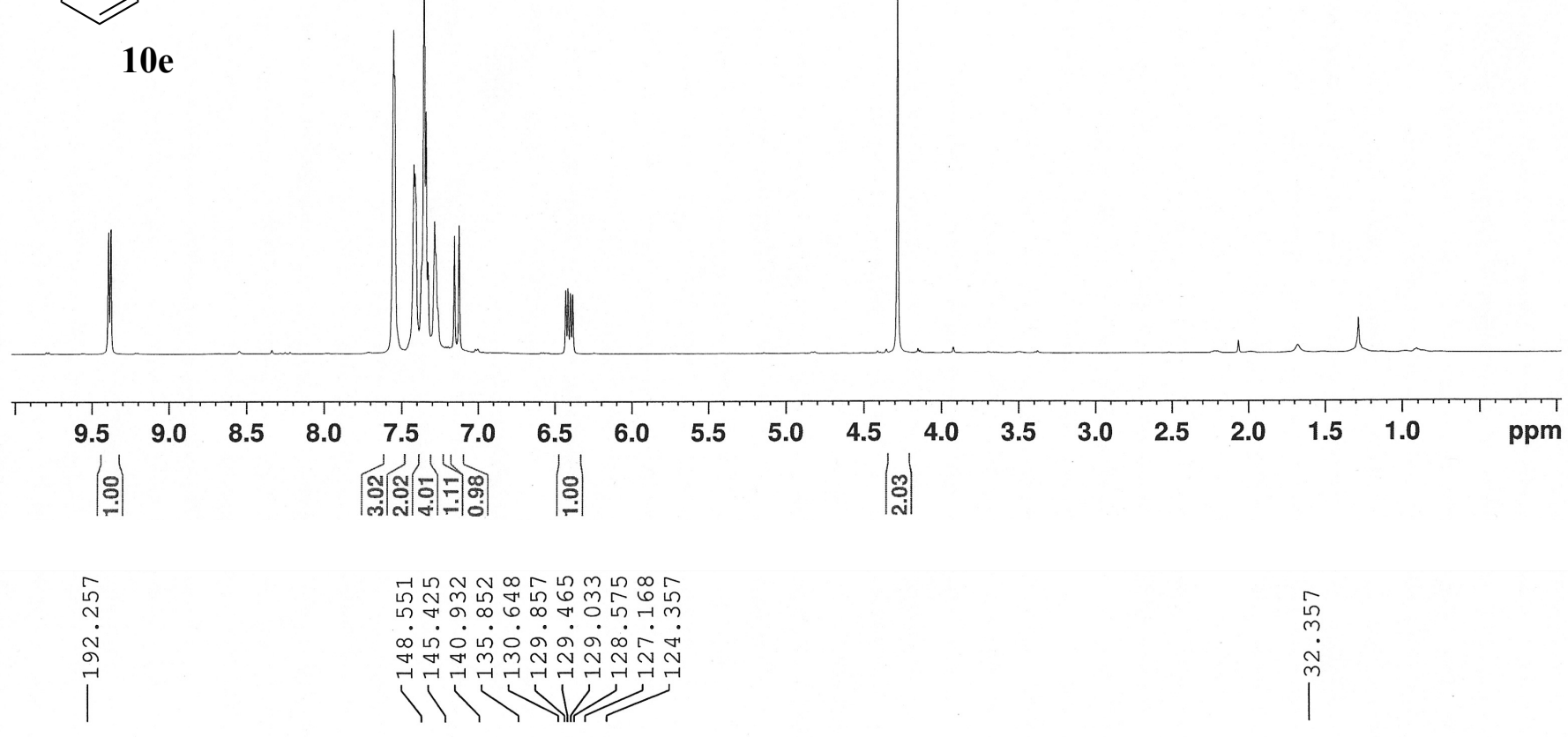<smiles>O=C/C=C/C(Cc1ccccc1)=[N+]([O-])c1ccccc1</smiles>

10e

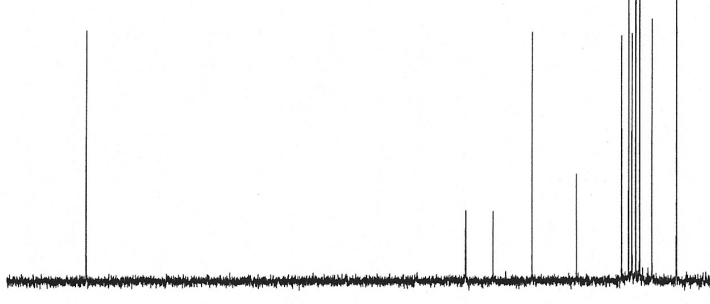




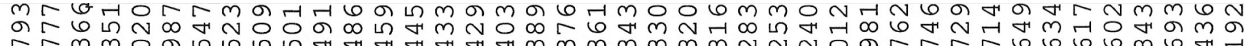

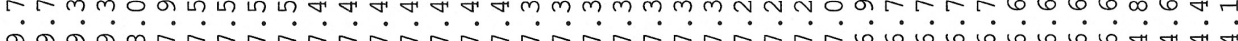

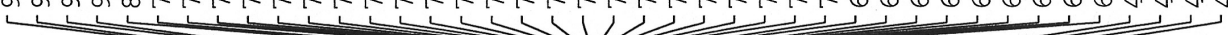

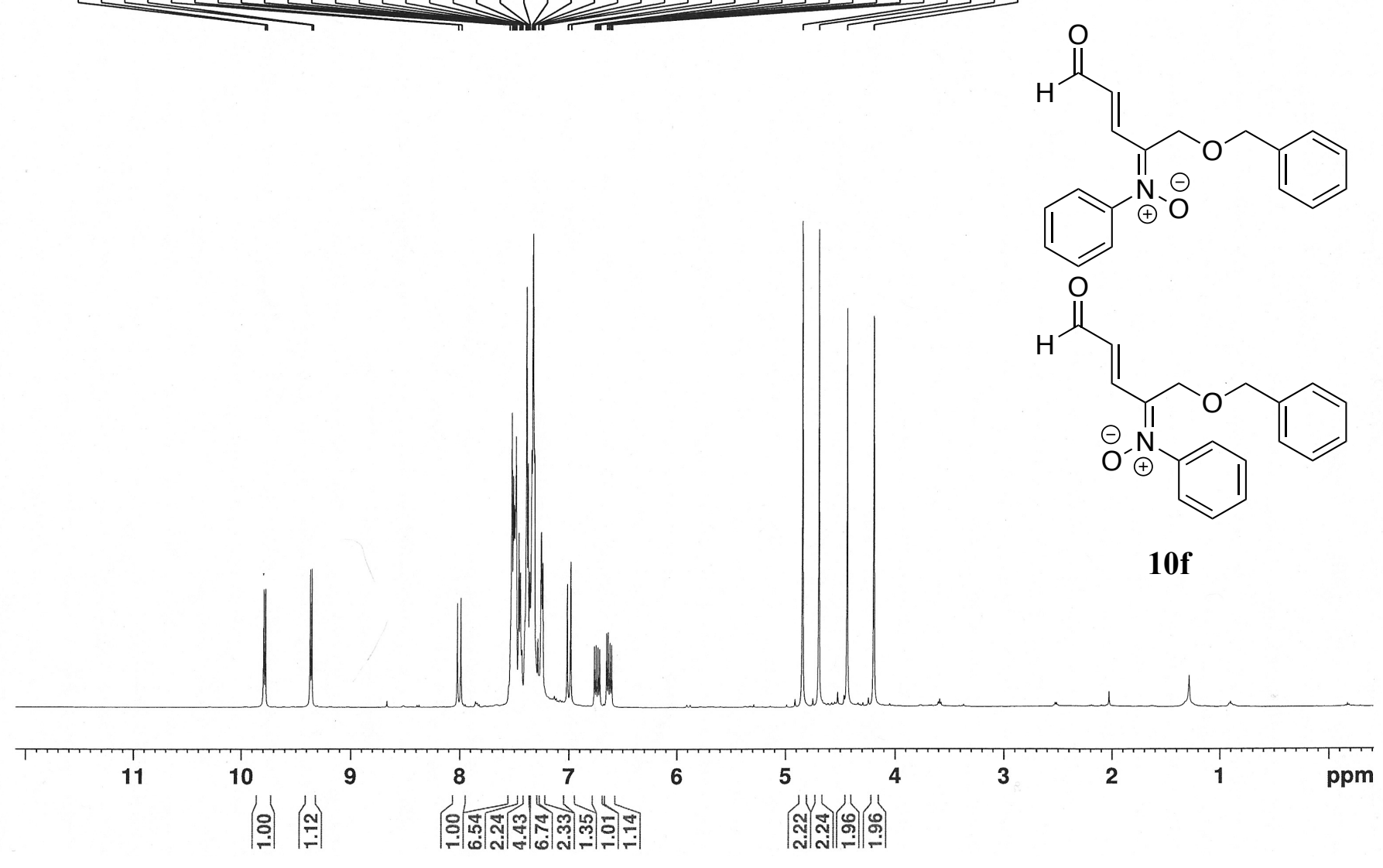

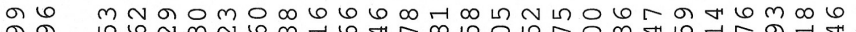

नิ

न

नु

1 红

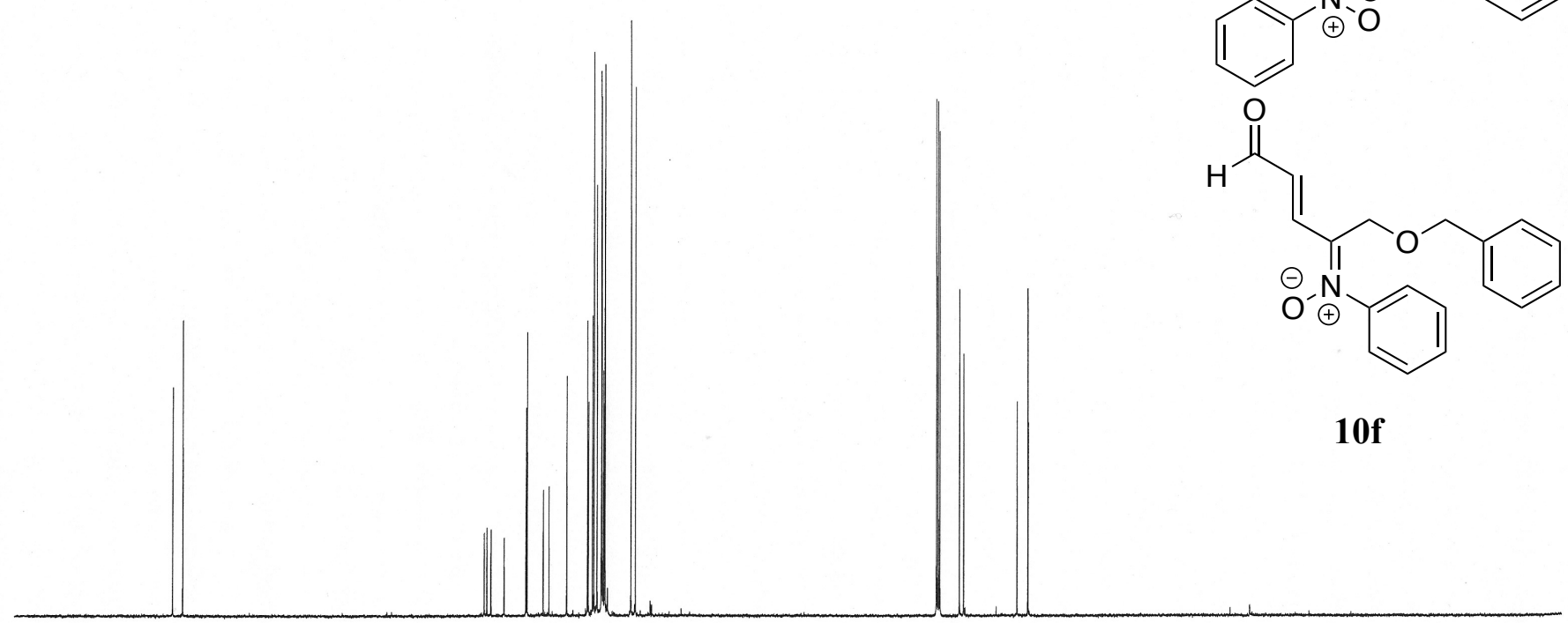




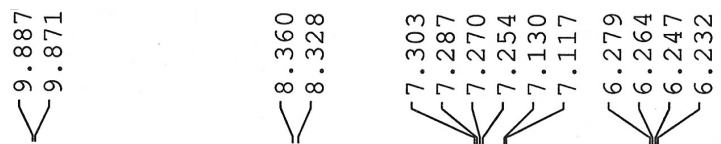<smiles>O=C/C=C/C(=C(/c1ccccc1)[N+](=O)[O-])c1ccccc1</smiles>

10g'
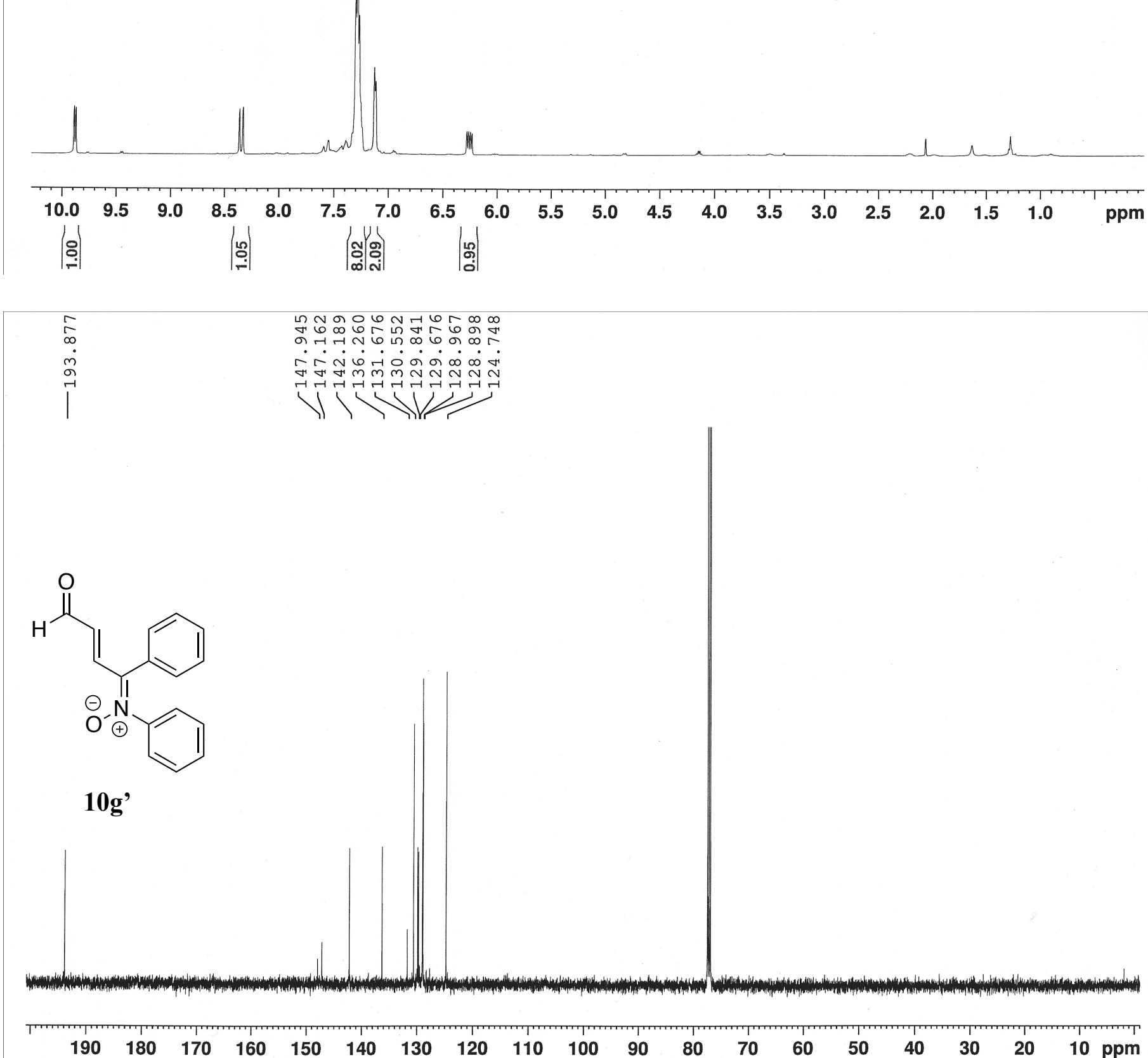

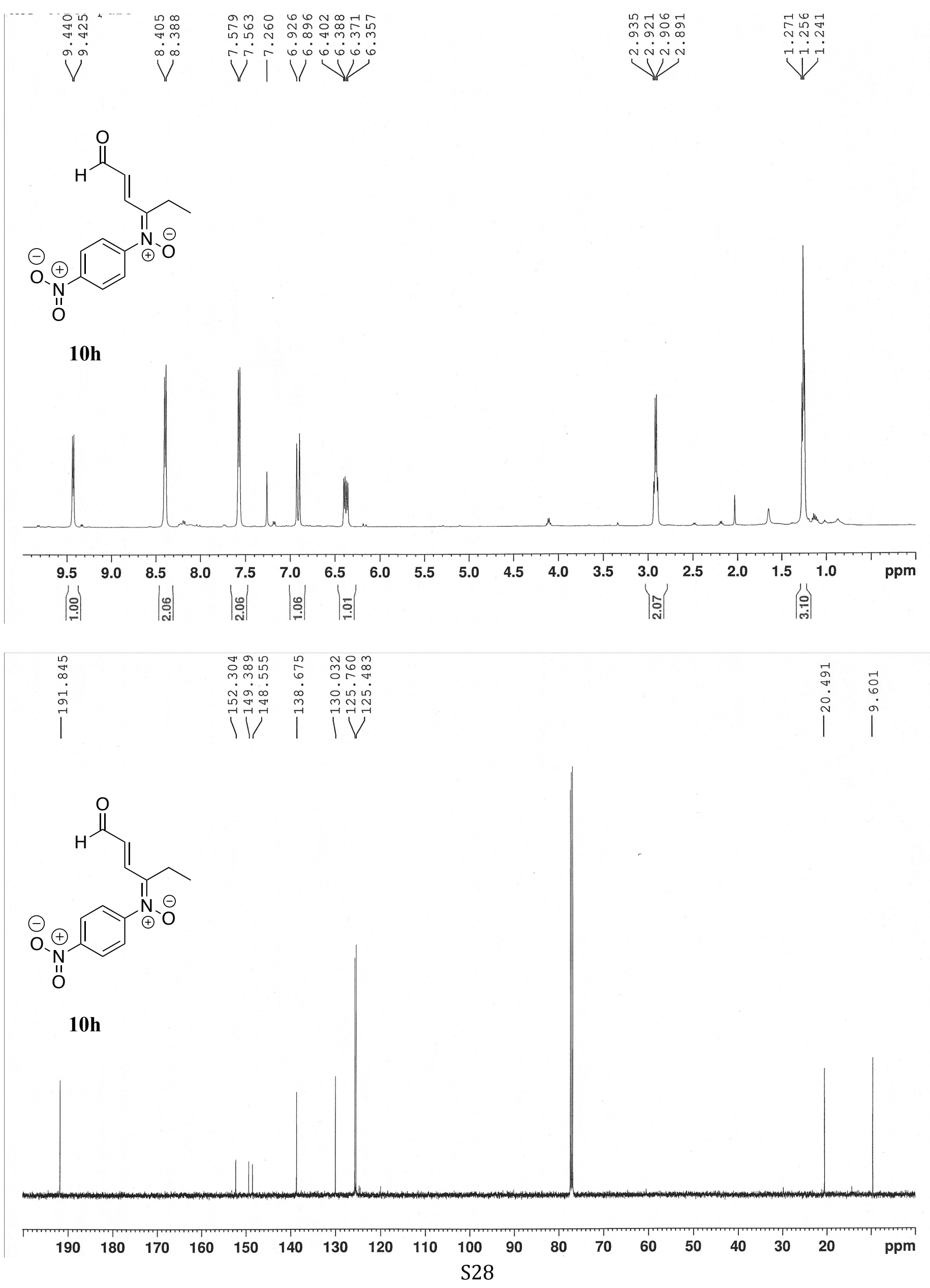


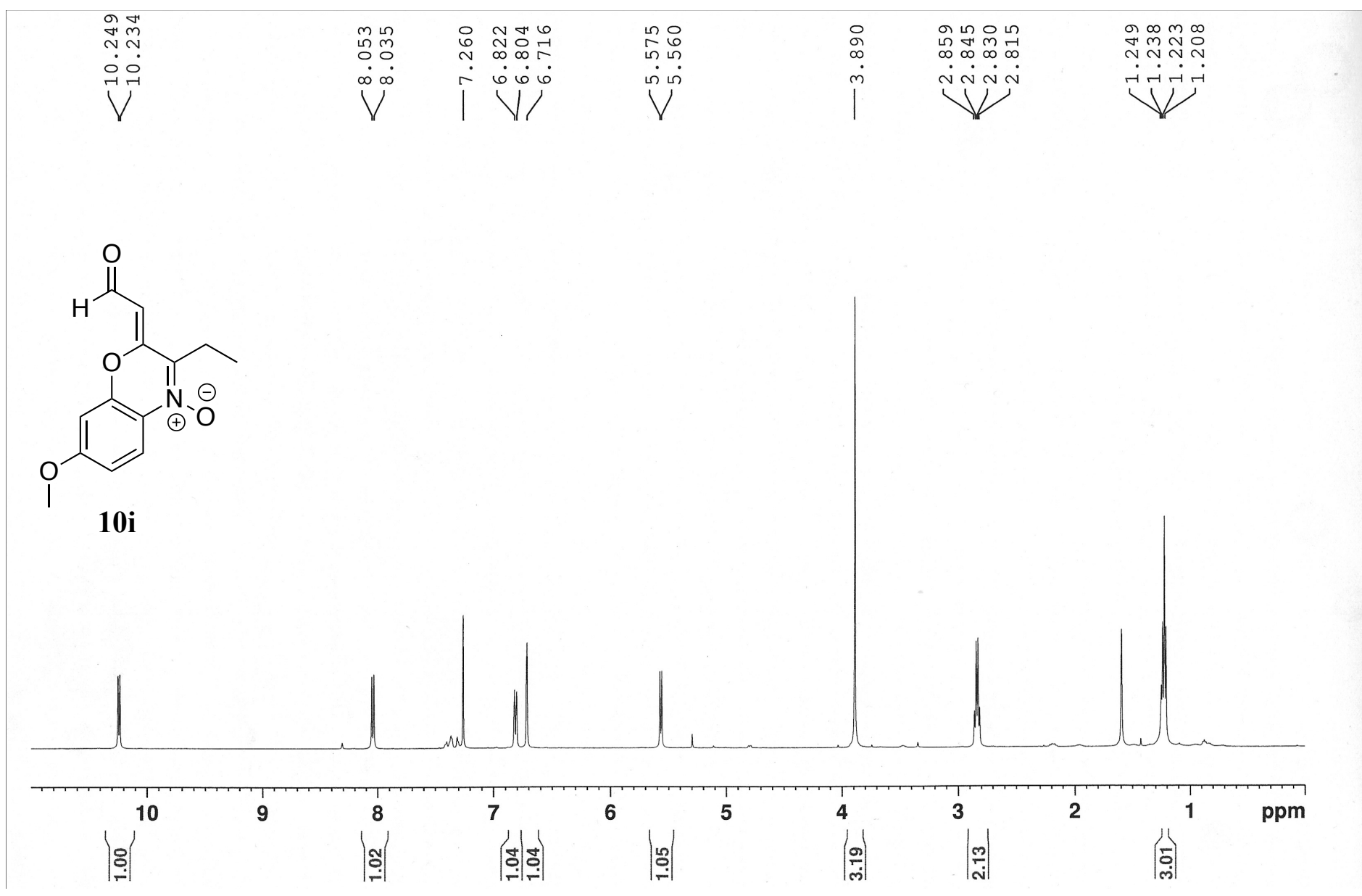

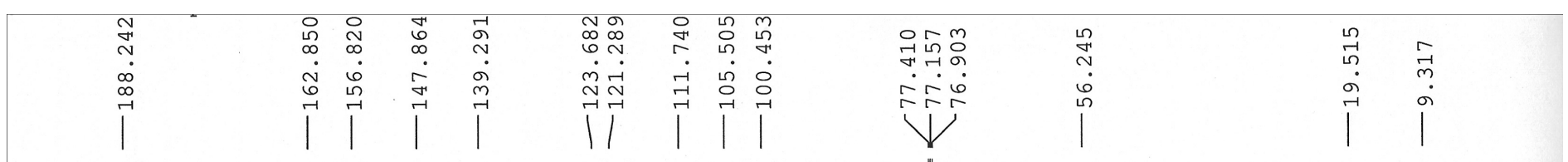<smiles>CCc1c(C=O)oc2cc(OC)ccc2[n+]1=O</smiles>

$10 \mathrm{i}$

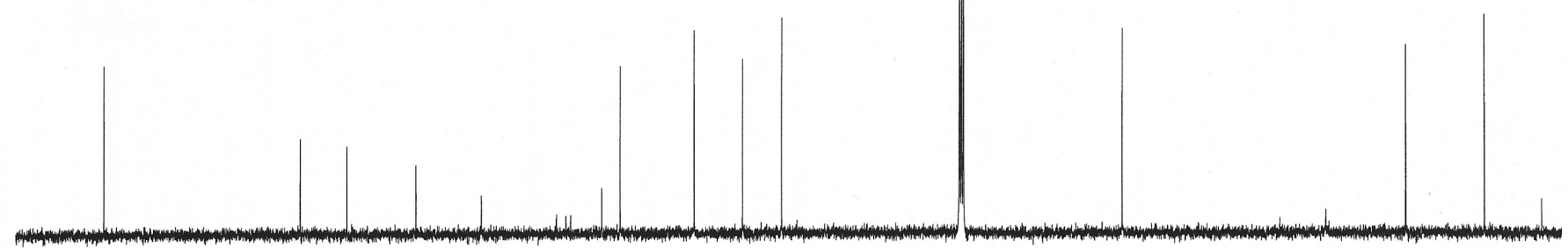




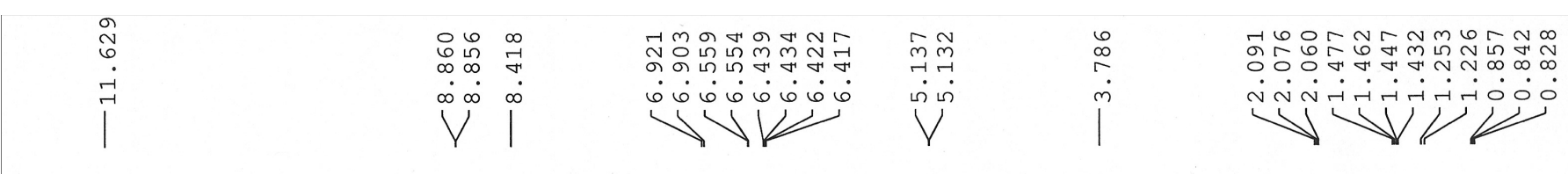<smiles>CCC/C(=C/C=O)Nc1ccc(OC)cc1O</smiles>

11

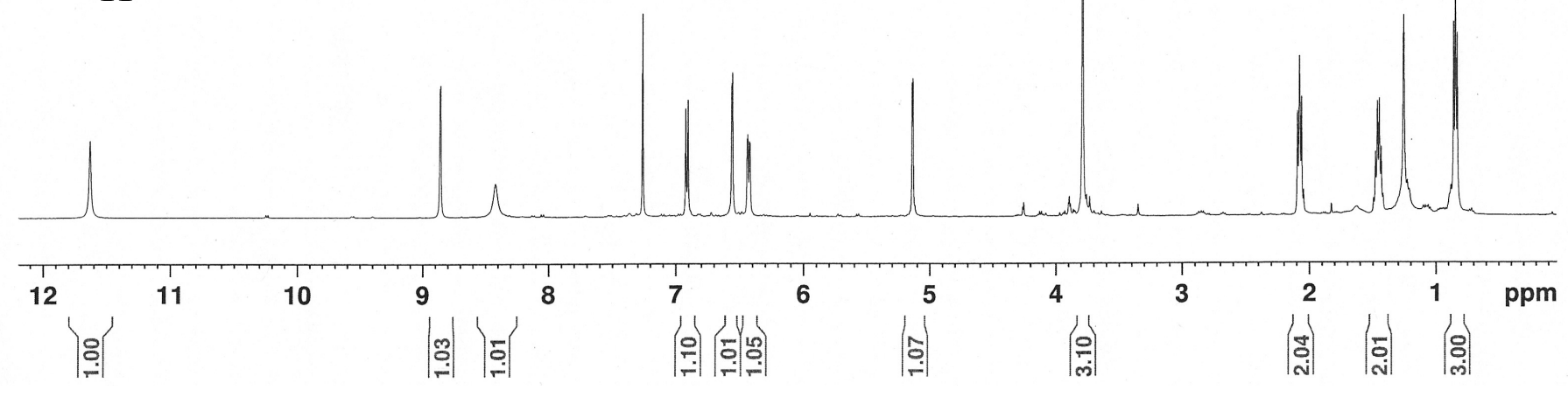<smiles>CCC/C(=C/C=O)Nc1ccc(OC)cc1O</smiles>

11
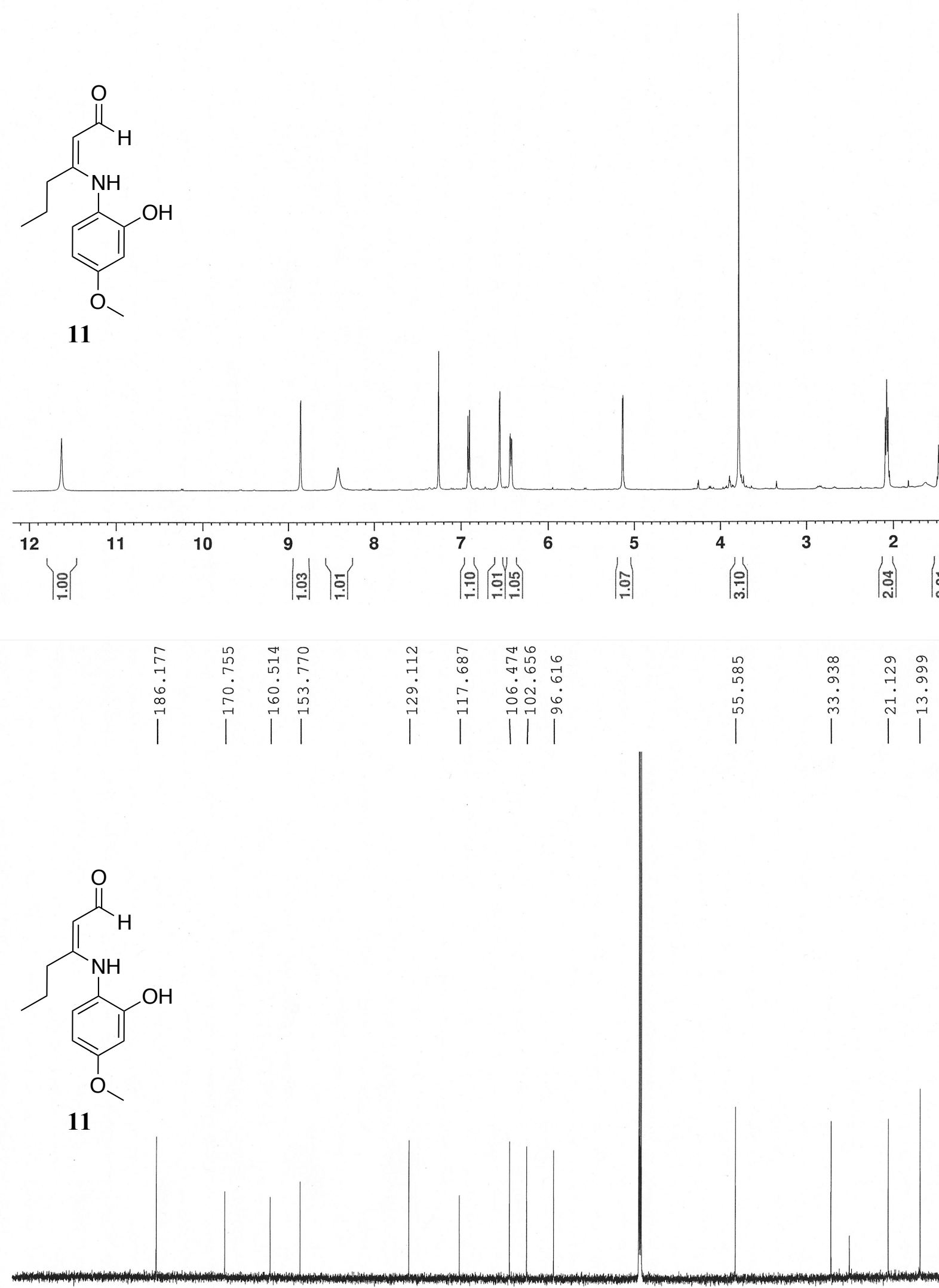

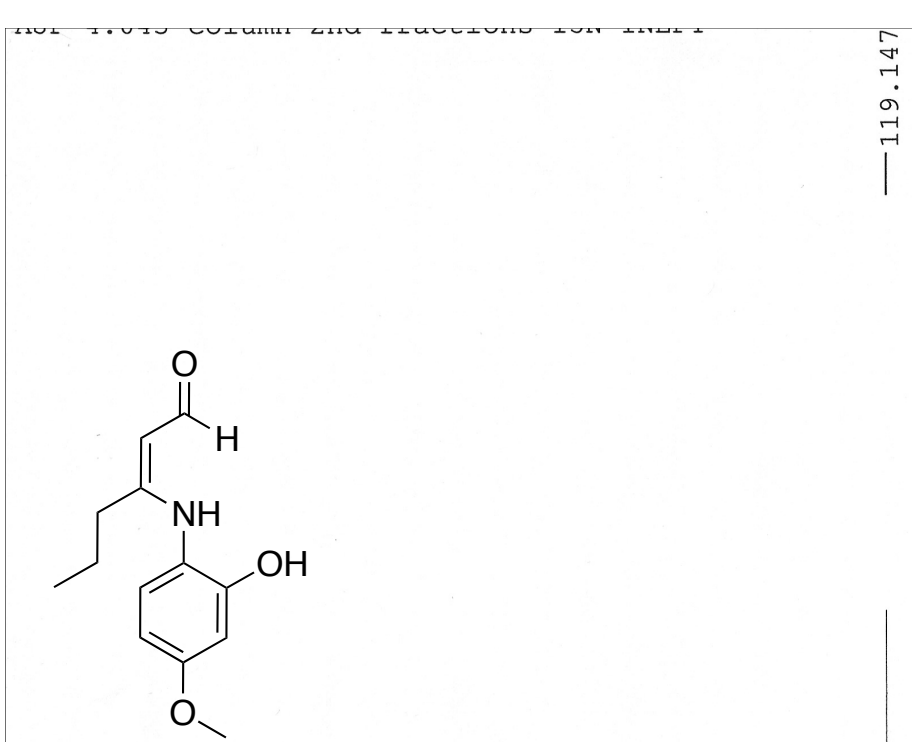

11

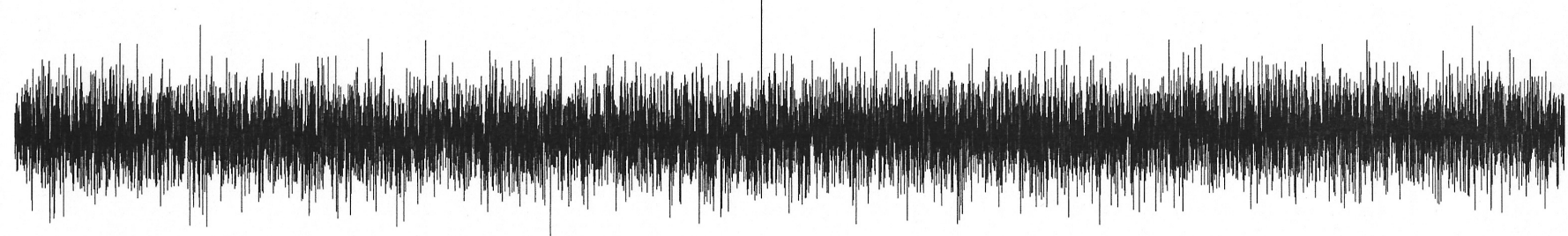

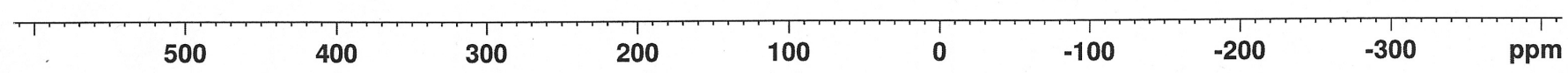



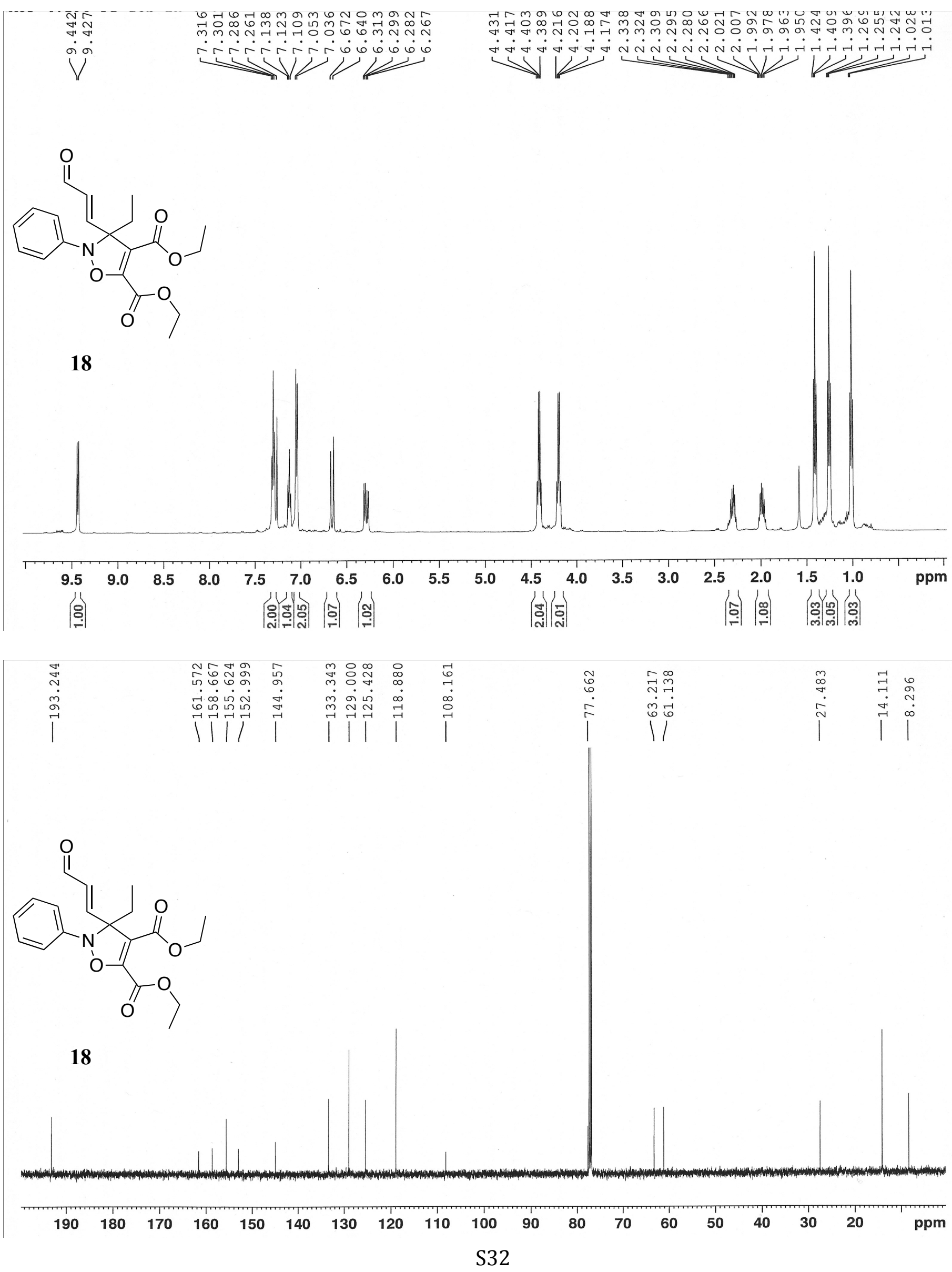


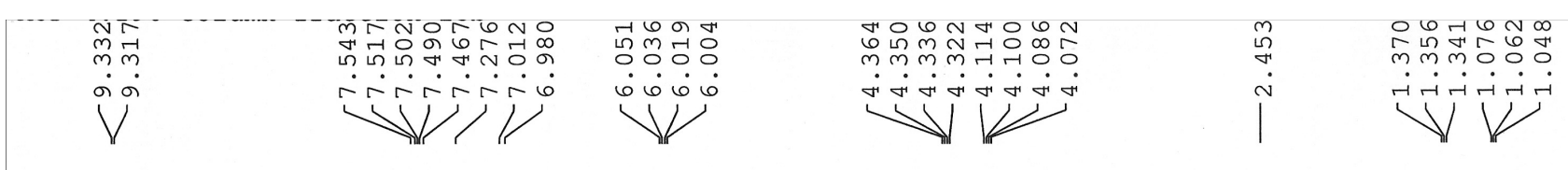<smiles>CCOC(=O)c1c(C)c(/C=C/C=O)n(-c2ccccc2)c1C(=O)OCC</smiles>

19

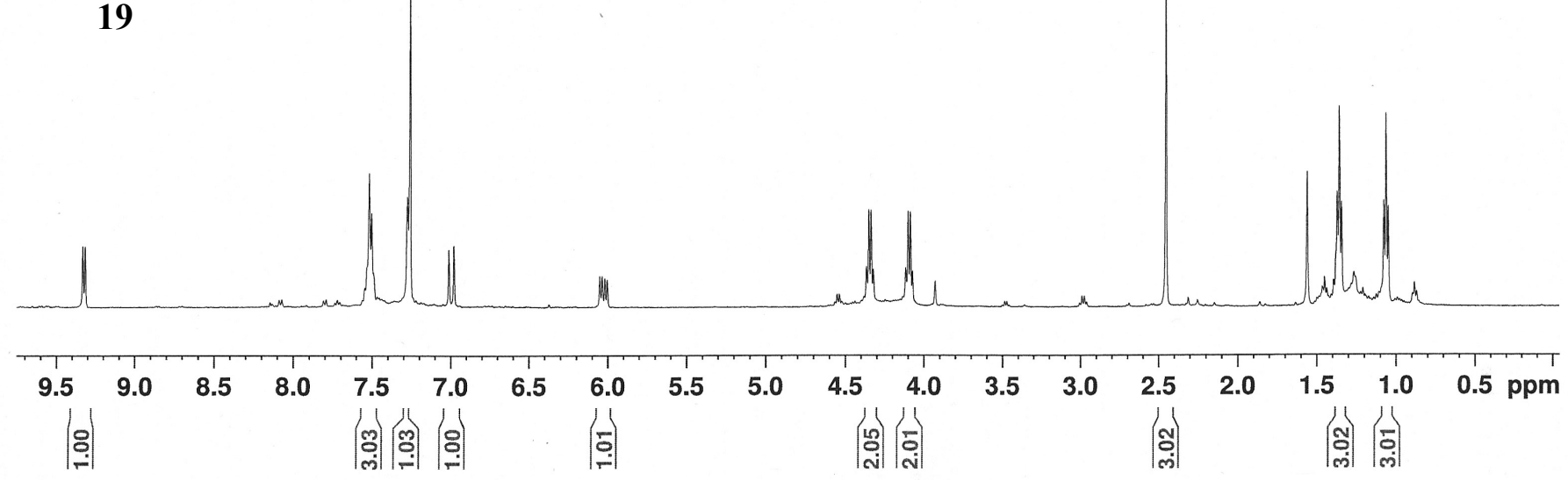

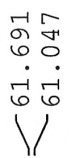

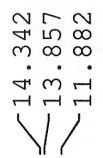<smiles>CCOC(=O)c1c(C)c(/C=C/C=O)n(-c2ccccc2)c1C(=O)OCC</smiles>

19
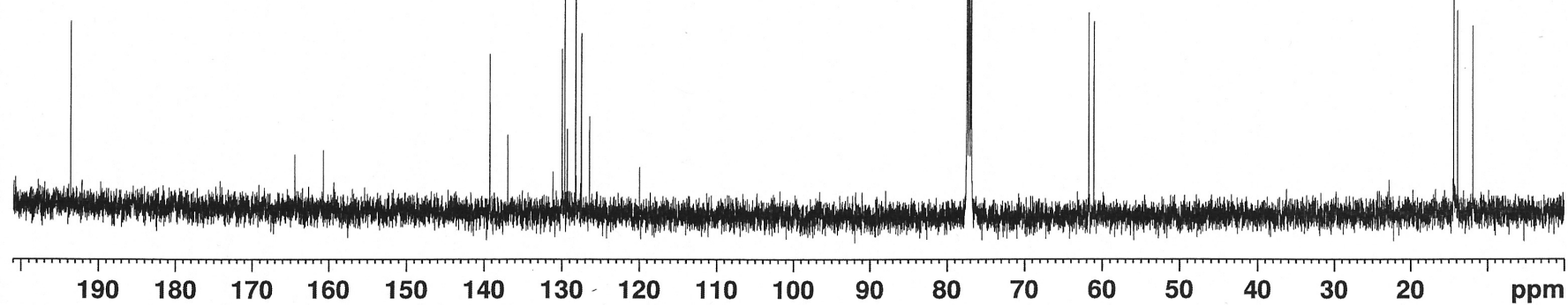


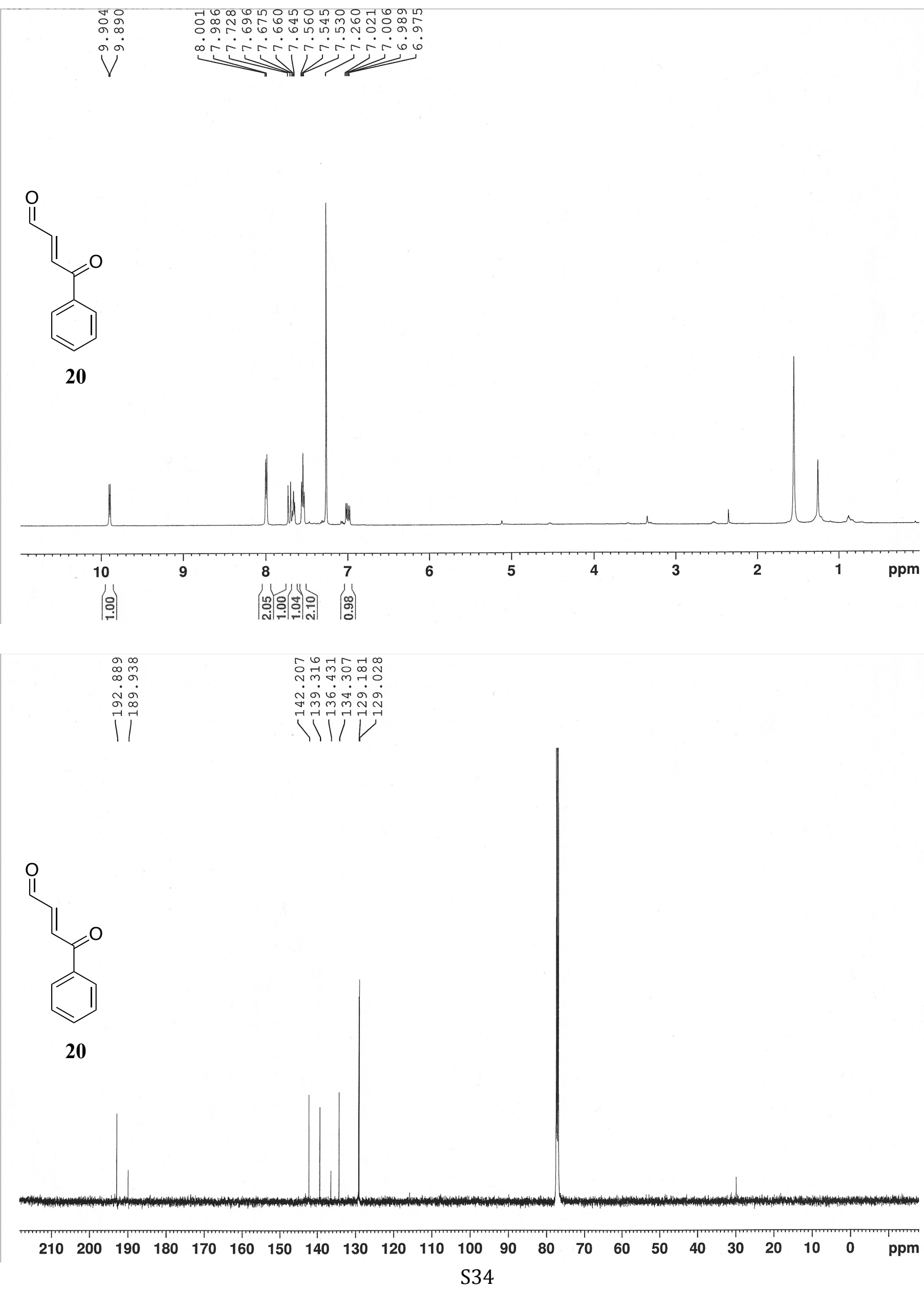


<smiles>CCCC1C[C@H](O)ON1c1ccccc1</smiles>

17
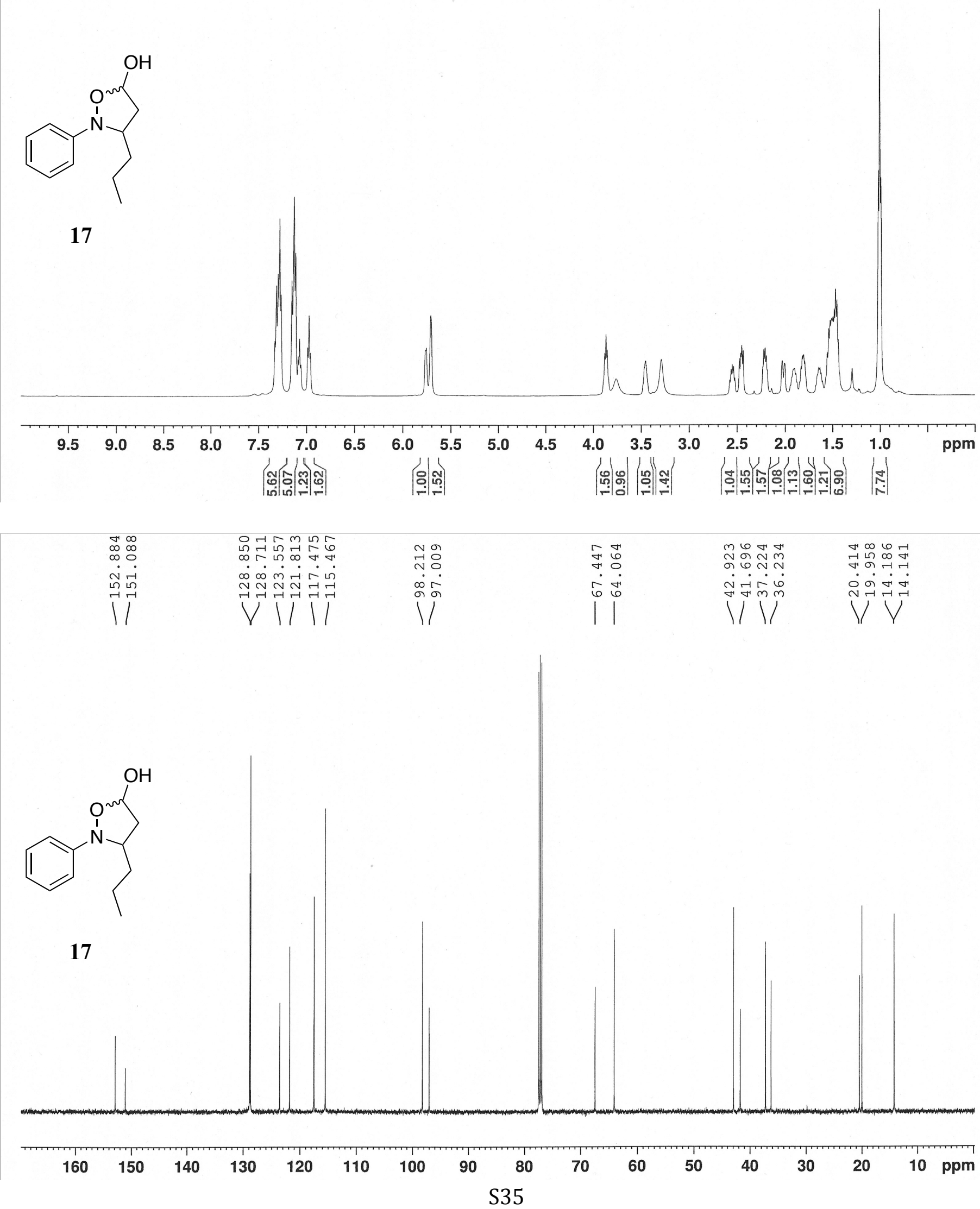

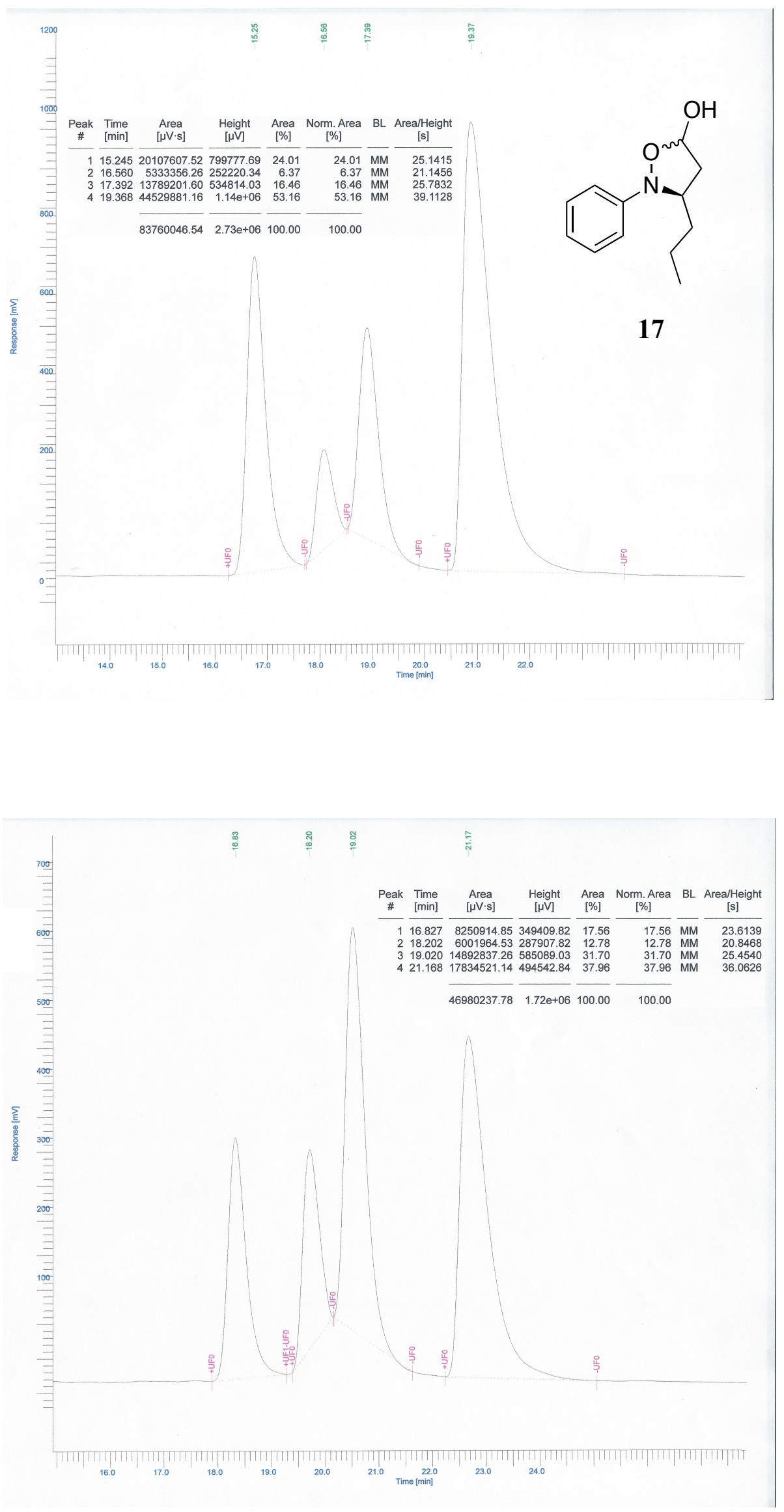